\title{
A TEORIA DA CEGUEIRA DELIBERADA: QUANTO À ORIGEM ÍLICITA DO OBJETO MATERIAL DO CRIME
}

\author{
Rita de Cássia Silva Paz* \\ Professor Bruno Aparecido Souza**
}

RESUMO

O presente trabalho tem por objetivo, em um primeiro momento, pontuar as principais características presentes na Teoria da Cegueira Deliberada, norteando comparativamente para com o crime de receptação, devidamente tipificado no Código Penal, detalhando, inclusive, as diferenças quanto à ocorrência do dolo eventual e a culpa consciente. Após as devidas caracterizações de cada instituto, o foco passa a ser a descaracterização da modalidade culposa, quando a alegação de desconhecimento por parte do réu, em que poderia ser suficiente para absolvição no crime de receptação, e por outro lado, um fundamento de grande importância para condenar o agente, utilizando as características da Teoria da Cegueira Deliberada. Para demonstração de forma clara e sucinta, relata-se a aplicação da teoria norte-americana em casos concretos ocorridos no Brasil, as investigações ocorreram pelo crime de lavagem de dinheiro. A condenação se tornou possível, a partir do momento da alegada falta de conhecimento. Ao fim, foram feitas algumas observações quanto ao crime tipificado na Lei 9.613/98, qual seja, crime de lavagem de capitais, detalhando as medidas que eventualmente possam ser tomadas para o ressarcimento das vítimas.

Palavras-chave: Teoria da Cegueira Deliberada. Crime de Receptação. Dolo Eventual e Culpa Consciente. Casos Ocorridos no Brasil. Lavagem de dinheiro.

\section{THE THEORY OF BLINDED BLINDNESS: AS THE UNLICITED ORIGIN OF THE MATERIAL OBJECT OF CRIME}

\section{ABSTRACT}

The present work aims, at first, to point out the main characteristics present in the Theory of Deliberated Blindness, comparatively guiding with the crime of Reception, duly typified in the Penal Code, detailing, also, the differences regarding the occurrence of the possible fraud and conscious guilt. After the proper characterization of each institute, the focus becomes the mischaracterization of the culpable modality, when the allegation of ignorance on the part of the defendant, in which it could be sufficient for absolution in the crime of

* Formada em Direito, pela Universidade Metodista de São Paulo, atualmente trabalha como Assistente Jurídico no escritório Evangelista Sociedade Individual de Advocacia. E-mail para contato: rita.spaz@outlook.com

** Advogado. Professor, de Direito Penal e Processo Penal da Universidade Metodista de São Paulo. Pós-graduado em Direito Penal e Direito Processual Penal pela Faculdade Damásio de Jesus. Mestrando em Direito da Saúde, pela Universidade Santa Cecília. 
reception, and on the other hand, a great foundation importance to condemn the agent, using the characteristics of the Deliberate Blindness Theory. For demonstration in a clear and succinct way, it is reported the application of American theory in specific cases that occurred in Brazil, the investigations occurred for the crime of money laundering. The conviction became possible, from the moment of the alleged lack of knowledge, at the end, some observations were made regarding the crime typified in Law 9.613 / 98, that is, the crime of money laundering, detailing the measures that may eventually be taken for the compensation of the victims.

Keywords: Theory of Deliberate Blindness. Crime of Reception. Eventual Intent and Conscious Guilt. Cases occurred in Brazil. Money laundry.

\section{INTRODUÇÃO}

A teoria da Cegueira Deliberada, também denominada de Ostrich Instruction, que, em tradução literal, significa - "instrução da avestruz", referindo-se ao ato de o animal esconder sua cabeça quando em situação de perigo (IRA, 1990), é pouco compreendida, senão abalizada no ordenamento jurídico brasileiro, haja vista não existir previsão da prática no âmbito do Direito Penal.

Observe-se, contudo, que, conquanto não seja expressamente assinalada em nosso ordenamento jurídico, determinada inexistência não deve ser concebida como indiscutivelmente inocorrente e/ou se ocorrente, apenas em menor escala.

Contextualize-se, circunstancialmente, em termos práticos, que a teoria em discussão é, exatamente, o caminho legitimado (por criminosos) para se evitar qualquer - possível, senão, efetiva - responsabilização criminal.

Para melhor compreensão dessa, cognominemos - sobressaída, denota-se essencial referenciar o crime de receptação descrito no art. 180, do Código Penal, cuja tipificação prevê diferentes modalidades, com cominações sancionatórias diversas, em que o agente (receptador), desconsiderando-se propositalmente, ou seja, imbuído de dolo (vontade livre e consciente de receptar), a origem da 'coisa' que se lhe destina, objetivando, unicamente, dela beneficiar-se, viabiliza preteritamente, quando factível qualquer responsabilidade penal, sua ocorrência na forma privilegiada (caput, $\S \S \S 3^{\circ}, 4^{\circ}$ e $5^{\circ}$ ).

Acrescente-se, que o caput, refere-se a dolo genérico. Na dúvida, e não na certeza, sobre a origem da coisa, há incidência de receptação culposa. Some-se, ainda, nessa hipótese, a real possibilidade de se declarar extinta a punibilidade do agente, por intermédio do perdão judicial.

Resta, outrossim, indubitável, que os agentes assumem o risco do resultado, certos de que, na eventualidade de qualquer responsabilidade penal, esta se delimitará máxime, na modalidade culposa, qual, segundo Magalhães Noronha (2003, p. 518), o elemento psicológico pressupõe à vontade (livre) consciente de adquirir ou receber a coisa e, a culpa, em não assegurar o conhecimento preciso de sua proveniência. Noutras palavras, na imprudência, negligência ou imperícia, relacionada ao desconhecimento da origem do objeto.

Defendemos, contudo, que tal comportamento deve-se submeter à caracterização do dolo-eventual, pois, o agente presume a caracterização do fato delituoso, 
assumindo, deliberadamente, o risco do resultado. Neste sentido, compreende-se totalmente possível, a averiguação de todas as etapas realizadas e/ou superadas pelo agente (iter criminis), possibilitando a individualização do dolo em cada uma delas.

No assalto ao Banco Central de Fortaleza (CE), ocorrido no ano de 2005, considerado até os dias atuais "O maior roubo da história do Brasil", deixa clara a ocorrência da cegueira diretamente suplementada pelos vendedores de automóveis, que aceitaram prontamente a quantia oferecida em espécie pelos criminosos, para a aquisição de 11 veículos. Mesmo com toda a repercussão do caso em tela, a venda dos carros em detrimento da possibilidade de receber a quantia de um milhão de reais em dinheiro, cegaram os proprietários da concessionária, que não pensaram nas consequências, mesmo sabendo (ou devendo saber) que elas poderiam existir, assumiram o risco dos resultados ao realizarem a venda, sem atribuírem ostensivamente a devida importância ao que estava ocorrendo. Destaque-se, cuja repercussão foi de caráter internacional.

Acrescente-se, outrossim, que a teoria - raramente incidente no nosso acervo jurisprudencial -, incentiva a prática da receptação (dolosa), oportunizando, inclusive, sua respectiva reponsabilidade na modalidade culposa $\left(\$ 3^{\circ}\right)$, quando deveria, exatamente, em razão de sua instituição originária, assegurar objetivamente inexorável punição daqueles que, por ela, tencionam se furtar.

Não menos importante, será, nas entrelinhas demonstrar a responsabilidade (ou não) daqueles que efetivamente desconhecem a prática da conduta criminosa, de modo que incidirão no erro de tipo (art. 20, CP), haja vista a semelhança existente entre aquele que dolosamente se cegou para a origem do objeto e aquele que não detinha condições de conhecê-lo.

Finalmente, necessário se fará diferenciar as práticas delituosas (receptação/ cegueira), bem como, os motivos que permitirão presumir se o agente tinha ou deveria ter conhecimento sobre a conduta que realizou, utilizando-se, sugestivamente de casos ocorridos em âmbito nacional, com os seus respectivos desfechos.

\section{TEORIA DA CEGUEIRA DELIBERADA}

Na parte histórica da criação da Teoria da Cegueira Deliberada, o surgimento se deu na Inglaterra, no ano de 1861, no caso do Sr. Sleep, um embarcador que colocou barris com parafusos de cobre que continham uma flecha para baixo em uma embarcação mercantil, sendo que o símbolo era característico de objetos que pertenciam ao Estado; neste sentido, foi denunciado pela prática de desvio de bens públicos.

Obviamente foi condenado, momento em que interpôs recurso, alegando o desconhecimento de tal fato, e por falta de provas de que o Sr. Sleep havia, de fato, se desatentado intencionalmente do detalhe gravado nos barris, a decisão foi reformada. De forma clara, se houvessem indícios comprobatórios do desconhecimento proposital, a decisão seria mantida.

Em meados do século XIX, a doutrina inglesa já havia pacificado o entendimento acerca da ligação entre a Cegueira Deliberada e o conhecimento do agente, mais especificadamente, da intenção em ignorar o conhecimento. 
Nos Estados Unidos, a teoria se fez presente em 1899, no caso do Sr. Spurr, que estava sendo investigado pelo Estado, ao ter certificado cheques de um cliente que não possuía fundos em sua conta bancária, que foi considerado culpado por tal conduta. Em contrapartida, em sede de recurso, a defesa alegou que o magistrado não demonstrou de forma clara e objetiva, que a intenção do Sr. Spurr era ignorar fatos penalmente relevantes.

Acerca deste caso, o Tribunal Supremo acolheu a tese interposta na defesa, fundamentou que o Magistrado de fato não especificou que o agente teria ignorado a insuficiência de fundos na conta de seu cliente ou que, sequer, tenha se mostrado indiferente a tais circunstâncias.

Em 2001, a Teoria da Cegueira Deliberada é utilizada na Espanha, em um processo em que o agente foi condenado pelo crime de receptação, ao transportar uma boa quantia em dinheiro, alegando o desconhecimento da origem do dinheiro, que era oriundo do tráfico de drogas, a decisão da Turma se fundou nas alegações abaixo:

Na entrega do dinheiro a José J., Miguel foi acompanhado por Hebe, e José J. cobrou uma comissão de 4\%. A Câmara conclui que José J. sabia que o dinheiro vinha do negócio de drogas - o que ele nega - de fatos óbvios, como o valor era muito importante e a natureza claramente clandestina das operações, portanto. Quem se coloca em uma situação de ignorância deliberada, ou seja, não quer saber o que pode e deve ser conhecido, e ainda assim se beneficia dessa situação - ele cobrou $4 \%$ de comissão - está assumindo e aceitando todas as possibilidades da origem do negócio quem participa e, portanto, deve responder por suas consequências ${ }^{1}$. (RAGUÈS I VALLÈS, 2013, p. 20). (tradução livre)

A utilização da teoria, na Espanha, foi objeto de fundamentação em várias causas que surgiram posteriormente, para embasar a condenação daqueles que negavam o conhecimento da origem ilícita, com a intenção de se safar da condenação.

No Brasil, a Teoria da Cegueira Deliberada foi adotada pela primeira vez no ano de 2005, no famoso crime do Assalto ao Banco Central do Ceará, em que o Magistrado de $1^{a}$ instância utilizou-se dos pressupostos que fazem parte da teoria, para fundamentar a condenação dos empresários e proprietários de uma concessionária, que venderam 11 veículos, sendo pagos em dinheiro, que totalizou o valor de $R \$$ 980.000,00 (novecentos e oitenta mil reais), que, posteriormente, foi descoberto que $o$ dinheiro utilizado para a compra dos veículos era oriundo do furto ocorrido.

1 En la entrega del dinero a José J., Miguel estuvo acompañado de Hebe, y José J. cobrara un $4 \%$ de comisión. La Sala extrae la conclusión de que José J. tuvo conocimento de que el dinero procedía del negocio de drogas -cosa que él niega- de hechos tan obvios como que la cantidad era muy importante y de la natureza claramente clandestina de las operaciones, por lo que quien se pone en situación de ignorancia deliberada, es decir no querer saber aquello que puede y debe conocerse, y sin embargo se beneficia de esta situación -cobraba un 4\% de comisión-, está asumiendo y aceptando todas las posibilidades del origen del negocio em que participa, y por tanto debe responder de sus consecuencias. 
Neste caso, em recurso destinado ao Tribunal Regional Federal da 5 a região, os empresários foram absolvidos, vez que o furto ocorreu de sexta para o sábado, e os veículos foram comprados na manhã de sábado - porém, o crime só foi descoberto quando iniciou-se o horário bancário, o que afasta a possibilidade de manter a condenação dos proprietários, vez que não havia indícios de que o dinheiro se relacionaria com um assalto, que sequer havia sido descoberto. Conforme trecho da decisão da apelação criminal ACR5520-CE, processo de número 001458640.2005.4.05.8100, abaixo colacionada:

(...) a transposição da doutrina americana da cegueira deliberada (willful blindness), nos moldes da sentença recorrida, beira, efetivamente, à responsabilidade penal objetiva; não há elementos concretos na sentença recorrida que demonstrem que esses acusados tinham ciência de que os valores por ele recebidos eram de origem ilícita, vinculada ou não a um dos delitos descritos na Lei $n^{\circ} 9.613 / 98$. O inciso II do $\S 2^{\circ}$ do art. $1^{\circ}$ dessa lei exige a ciência expressa, e não apenas o dolo eventual. Ausência de indicação ou sequer referência a qualquer atividade enquadrável no inciso II do $\S 2^{\circ}$. Não há elementos suficientes, em face do tipo de negociação usualmente realizada com veículos usados, a indicar que houvesse dolo eventual quanto à conduta do art. $1^{\circ}, \S 1^{\circ}$, inciso II, da mesma lei; na verdade, talvez, pudesse ser atribuída aos empresários a falta de maior diligência na negociação (culpa grave), mas não dolo, pois usualmente os negócios nessa área são realizados de modo informal e com base em confiança construída nos contatos entre as partes. (TRF-5 - ACR: 5520 CE 0014586-40.2005.4.05.8100, Relator: Desembargador Federal Rogério Fialho Moreira, Data de Julgamento: 09/09/2008, Segunda Turma, Data de Publicação: Fonte: Diário da Justiça - Data: 22/10/2008 - Página: 207 - No: 205 - Ano: 2008)

A Cegueira Deliberada é conhecida por diversas expressões, como: Willful Blindness Doctrine (Doutrina da cegueira intencional), Ostrich Instructions (instruções de avestruz), Conscious Avoidance Doctrine (doutrina do ato de ignorância consciente), "Teoria das instruções da Avestruz", dentre outros.

Todas as nomenclaturas são destinadas ao mesmo conceito, vez que, tal teoria é utilizada para demonstrar quando o agente propositalmente, ou seja, dolosamente "fecha os seus olhos" para o ato ilícito que está diante de sua visão, unicamente com o intuito de obter vantagem, sem que seja dada a devida importância ao que está sendo praticado, visando somente o resultado que será atingido.

A relação auferida ao avestruz diz respeito ao ato realizado pelo animal, que ao se sentir em situação de perigo, enterra a sua cabeça para se proteger.

Basicamente, a teoria foi criada no intuito de punir os agentes que alegam falaciosamente desconhecer a ilicitude do ato praticado. Assim, para que essa teoria seja aplicada, necessário se faz, considerando-se todos os elementos essenciais do fato, analisar se o desconhecimento da ilicitude se fundamenta em circunstâncias substanciais que permitam sua presunção absoluta. Doutro modo, para que na 
incidência de elementos circunstanciais suficientemente perceptíveis a gerar a desconfiança da origem ilícita da prática - para os quais o agente se negou a dar a devida importância, com o precípuo objetivo de obter a vantagem desejada - seja-lhe atribuída a responsabilidade pelo ilícito na modalidade dolosa.

Para Marco Antônio de Barros e Thiago Minetti Apostólico Silva, a Teoria da Cegueira deliberada:

\footnotetext{
Constitui uma tese jurídica por meio da qual se busca atribuir responsabilidade penal àquele que, muito embora esteja diante de uma conduta possivelmente ilícita, se autocoloca em situação de ignorância, evitando todo e qualquer mecanismos apto a conceder-lhe maior grau de certeza quanto a potencial antijuridicidade". (BARROS; SILVA, 2015, p. 203 - 256).
}

Sobre o mesmo assunto, Renato Brasileiro de Lima (2016, p.319) discorre: aquele que renuncia a adquirir um conhecimento hábil a subsidiar a imputação dolosa de um crime responde por ele como se tivesse tal conhecimento.

Assim, o estado de ignorância ao qual o agente se coloca, utilizando a teoria da Cegueira Deliberada, pode ser suficiente a ensejar o decreto condenação, pelo resultado que almejava alcançar.

Neste caso, deve-se observar a incidência do dolo eventual, por parte do agente praticante do ato, de modo que mesmo podendo se desvencilhar do ocorrido, prefere se colocar em estado de ignorância, objetivando satisfazer-se do resultado na obtenção de vantagem indevida.

Destarte, no direito penal brasileiro, entende-se que a cegueira deliberada se dá quando, voluntariamente, o agente afasta a apercepção, ou seja, suas suspeitas sobre a potencial origem ilícita do objeto, assumindo dessa forma os riscos inerentes ao ato que irá praticar.

Nas palavras de Sérgio Valladão Ferraz (2018, p. 368):

A configuração da cegueira deliberada depende, apenas, de que o agente, com o conhecimento suficiente para direcionar sua ação, aja (ativa ou passivamente) com a intenção de desconhecer elemento típico para que o delito seja cometido com ignorância penalmente relevante.

Portanto, sempre que circunstancialmente notável para o agente, sob a compreensão do homo medius, a ilicitude do que está lhe sendo proposto e, em detrimento de tal, opta pela continuidade da prática para alcançar o resultado que almeja, restará caracterizada a Cegueira Deliberada, permitindo-se, consequentemente, sua condenação com fundamento no elemento subjetivo doloso - vontade livre e consciente de alcançar o resultado, com base nesta teoria norte-americana.

\section{CRIME DE RECEPTAÇÃO}

O crime de receptação está devidamente tipificado nos artigos 180 e 180-A, do Código Penal Brasileiro, sendo possível constatar que, para a consumação do crime de receptação, exige-se a plena consciência de que o objeto é de origem criminosa. Isto, porque, trata-se de tipo penal acessório, que por sua vez, necessita da consumação de crime anterior para a sua devida caracterização. 


\section{Guilherme Nucci, em sua obra Código Penal Comentado, aduz o seguinte:}

(...) receptação própria - é formada pela aplicação alternativa dos verbos adquirir (obter, comprar), receber (aceitar em pagamento ou simplesmente aceitar), transportar (levar de um lugar a outro), conduzir (tornar-se condutor, guiar), ocultar (encobrir ou disfarçar), tendo por objeto material coisa produto de crime. Nesse caso, tanto faz o autor praticar uma ou mais condutas, pois responde por crime único. (...) receptação imprópria - é formada pela associação da conduta de influir (inspirar ou insuflar) alguém de boa-fé a adquirir (obter ou comprar), receber (aceitar em pagamento ou aceitar) ou ocultar (encobrir ou disfarçar) coisa produto de crime. Nessa hipótese, se o sujeito influir para que a vítima adquira e oculte a coisa produto de delito, estará cometendo uma única receptação. (...) (NUCCI, 2017, p. 646).

Dentre as cominações previstas em ambos artigos, supracitados, há a previsão do crime na modalidade qualificada e na modalidade culposa. $\mathrm{O} \S 1^{\circ}$, do art. 180, do Código Penal, trata da modalidade qualificada, que é caracterizada pelo fato de que a pessoa, em situação de empresário, adquire o produto oriundo de crime anterior, para proveito na atividade comercial exercida, incluindo nesse caso, as atividades que estão de forma irregular, clandestino ou na própria residência.

Neste sentido, o entendimento do autor Fernando Capez destaca:

A lei pretendeu punir não apenas quem sabe, mas até mesmo aquele que devia saber. Foi além, portanto; previu como qualificadora mais do que o dolo direto, razão pela qual a conduta de quem sabe encontra-se embutida na de quem deve saber, de fora que o $\S 1^{\circ}$ do art. 180 alcança tanto o dolo direto (sabe) quanto o dolo eventual (deve saber). Não se trata de analogia ou interpretação extensiva, mas de declarar o exato significado da expressão ("deve saber" inclui o "sabe"), interpretação meramente declarativa, portanto. Se aquele que devia saber comete o crime, com maior razão responderá pela receptação qualificada o sujeito que sabia da origem ilícita do produto". (CAPEZ, 2016, p. 625).

Quanto à modalidade culposa, prevista no $\$ 3^{\circ}$, do artigo 180 , em que o agente poderia presumir que o produto que está lhe sendo apresentado é de origem criminosa - seja pelo valor cobrado, pela natureza ou pela pessoa que está lhe entregando -, acarreta detenção de um mês a um ano, ou multa, ou ambas as penas.

Para caracterização da modalidade culposa, nas palavras de Guilherme Nucci, o agente deve se ater ao:

(...) a) adquirir coisa que, pela sua natureza, deve presumir-se obtida por meio criminoso; $b$ ) receber coisa que, pela sua natureza, deve presumir-se obtida por meio criminoso; c) adquirir coisa que, pela desproporção entre o seu valor e o preço pago, deve presumir-se obtida por meio criminoso; d) receber coisa que, pela desproporção entre o seu valor e o preço pago, deve presumir-se obtida por meio criminoso; e) adquirir coisa que, pela condição de quem a oferece, deve presumir-se obtida por 
meio criminoso; f) receber coisa que, pela condição de quem a oferece, deve presumir-se obtida por meio criminoso.(...) (NUCCI, 2017, p. 646).

Portanto, é possível verificar o fator dominante quanto à caracterização do crime, qual seja, o saber ou, mais propriamente, o dever de saber a origem ilícita do produto ou serviço que está adquirindo, o que por muitas vezes pode gerar a absolvição do agente, no momento em que é alegado o desconhecimento da origem. Sendo assim, o desconhecimento de que há uma conduta ilícita praticada anteriormente pode gerar a absolvição - em contrapartida, será possível a condenação do agente utilizando a Teoria da Cegueira Deliberada, fundamentando justamente na alegação de desconhecimento.

\section{DIFERENÇA ENTRE OS INSTITUTOS}

Primeiramente, há de se verificar que, embora o crime de receptação esteja devidamente tipificado no Código Penal Brasileiro, sua caracterização, denomine-se, perfeita - que decorrerá consequentemente na punição do agente responsável pela prática dos verbos nucleares do tipo - depende da demonstração e comprovação do dolo, ou seja, a intenção do indivíduo, o real conhecimento de que o objeto da receptação advém de crime pretérito, e tão somente por essa razão poderá adquirir o produto que lhe está sendo oferecido, mediante pagamento de quantia inferior ao que o objeto realmente vale.

Obviamente, há circunstâncias que poderiam e, ao nosso entender, deveriam, ser observadas pelo receptador, como por exemplo, a fonte pela qual o objeto estava sendo-lhe oferecido, para que pudesse ao menos ter a desconfiança de que era proveniente, talvez, de um furto, ou até mesmo de um roubo.

O que se leva em consideração, contudo, é que se não houver a comprovação da má-fé no ato realizado pelo agente-receptador, haverá a possibilidade de uma condenação por receptação culposa, ou, em casos em que não há qualquer vestígio de tipicidade, nexo causal e/ ou culpabilidade, imputar a absolvição do acusado.

Diante disso, clara e evidente a existência de uma lacuna nas tipificações previstas nos artigos 180 e 180-A, do Código Penal, haja vista que comprovada a boa-fé do acusado, da qual não se vislumbra qualquer complexidade, de modo que presumida possivelmente não irá responder pelo crime praticado, e é exatamente por esta razão, que a Teoria da Cegueira Deliberada poderá ser utilizada.

No entendimento de Nelson Hungria, ao que diz respeito à existência da boa-fé, em crimes de receptação:

(...) o que se faz mister é que a coisa seja proveniente de crime, e este não é apenas o crime originário, senão também a intercorrente receptação. Se, entretanto, a coisa vem a ser adquirida ou recebida por terceiro de boa-fé, que, por sua vez, a transmite a outrem, não comete este a receptação, ainda que tenha conhecimento de que a coisa provém de crime. Houve, em tal caso, uma interrupção ou solução de continuidade da situação patrimonial anormal criada pelo crime originário e mantida, acaso, por intercorrente receptação de má-fé (...). (HUNGRIA, 1958, p. 321) (grifos nossos). 
Como já dito, a receptação tem um caráter essencial de comprovar a intenção do agente, a existência do dolo. Já com relação à Teoria da Cegueira Deliberada, se for utilizada, poderá condenar o agente, mesmo que o dolo tenha sido na modalidade eventual.

A característica predominante da teoria é exatamente o poder de identificar o momento que o agente agiu com a intenção de adquirir o bem móvel, mesmo com todas as características de que há uma origem ilícita, literalmente fechando seus olhos para isso, e adquirindo a seu patrimônio o objeto, sem que se importe com a origem do mesmo.

É uma forma eficiente de responsabilizar aqueles que obtêm vantagem de uma forma ilícita, oportunizando ao Estado a eficácia da lei penal para condenar o indivíduo que, ao invés de recusar a possibilidade de adquirir produto que sabe ou deveria saber, ser oriundo de crime anterior, fecha seus olhos objetivando obter vantagem indevida dele decorrente. Se esse grupo não desconsiderasse todas as circunstâncias de que a origem do objeto é ilícita, colaborando para uma sociedade melhor ao recusar a compra desses objetos, crimes como o de receptação e, principalmente, o de lavagem de dinheiro, seriam dispensáveis de tipificação no Código Penal.

Nas palavras do Professor Francisco Sannini Neto:

Em nosso entendimento, independentemente da modalidade, a teoria da cegueira deliberada sempre poderá ser utilizada para reforçar a materialidade delitiva da conduta. Do contrário, dificilmente restaria caracterizado o delito previsto no artigo $\underline{180}$ do Código Penal, uma vez que os órgãos responsáveis pela persecução penal teriam imensa dificuldade em provar a ciência da origem ilícita por parte do agente, pois ainda não é possível ao Estado imiscuir-se no consciente das pessoas. (SANNINI NETO, 2013).

Portanto, no que concerne o Crime de Receptação, ao literalmente "deixar de lado" a vantagem indevida que o agente auferiu em face de terceiro, a Teoria da Cegueira Deliberada vem para fazer com que a prática realizada pelo agente seja devidamente caracterizada, discorrendo a sua ação de "fechar os olhos" para a origem ilícita da coisa alheia, seja devidamente conhecida, resultando na devida condenação do indivíduo.

\section{DOLO EVENTUAL, CULPA CONSCIENTE E A ELIMINAÇÃO DA MODALIDADE CULPOSA}

O dolo, propriamente dito, tem ligação direta com a vontade do indivíduo em causar o dano a outrem e ter a consciência de que a conduta que irá praticar gerará um resultado. De forma redundante, o dolo é a certeza do agente de que irá cometer um ato infracional, seja qual for o resultado, contra outra pessoa. De acordo com Fernando Capez (2001, p. 153), é a vontade e a consciência de realizar os elementos constantes do tipo legal. Mais amplamente, é a vontade manifestada pela pessoa humana de realizar a conduta. 
Dentre as diversas ramificações do dolo, o dolo eventual é a modalidade mais relevante para o presente trabalho, vez que se trata de uma possibilidade, em que o agente, embora não queira realizar o caráter elementar do tipo penal, assume o risco do resultado, ao praticar a conduta.

Neste caso, o autor do fato tem o conhecimento de que poderá resultar em um tipo penal, e mesmo assim, assume o risco de fazê-lo. Note-se, o agente tem pleno saber de que o que irá fazer resultará em um fato danoso a outra pessoa, e mesmo assim, realiza a conduta. Mesmo não sendo a sua real intenção em chegar ao resultado penal, ele pratica o ato. Nessa linha de raciocínio, Fernando Capez assegura: [...] Note-se que a culpa consciente difere do dolo eventual, porque neste o agente prevê o resultado, mas não se importa que ele ocorra (...). (CAPEZ, 2017, p. 153).

Na ocorrência do dolo eventual, de certa forma, pode-se dizer que ao realizar o ato, o indivíduo, mesmo sabendo dos riscos, acredita que esses podem não se concretizar. Bitencourt esclarece que:

(...) haverá dolo eventual quando o agente não quiser diretamente a realização do tipo, mas aceitá-la como possível ou até provável, assumindo o risco da produção do resultado (art. 18, I, in fine, do CP). No dolo eventual o agente prevê o resultado como provável ou, ao menos, como possível, mas, apesar de prevê-lo age aceitando o risco de produzi-lo (...). (BITENCOURT, 2012, p. 354).

A culpa consciente e o dolo eventual podem ser facilmente confundidos, haja vista o caráter elementar de que o autor da prática delitiva tem conhecimento do resultado que poderá causar. Porém, diferente do dolo eventual, a culpa consciente está presente quando o autor chega ao resultado por uma falta de atenção, ao realizar a conduta delitiva.

Para o já citado Professor Cezar Roberto Bitencourt:

(...) há culpa consciente, também chamada culpa com previsão, quando o agente conhece a perigosidade da sua conduta, representa a produção do resultado típico como possível (previsibilidade), mas age deixando de observar a diligência a que estava obrigado, porque confiava convictamente que ele não ocorrerá (BITENCOURT, 2012, p. 374)

Especificadamente, o fato de que o autor dos fatos possa prever um resultado, por si só não caracteriza a culpa consciente. Para que esta ocorra, deve existir o cuidado em não se alcançar o resultado desfavorável, vez que, para a culpa consciente, deve haver a imprudência do agente, a falta de cuidado em algum dos atos praticados, para que seja considerada a existência da culpa consciente.

Hans Wezel explica que:

Se o agente, prevendo, embora, o resultado, espera sinceramente que este não ocorra, não se pode falar de dolo, mas só de culpa. É a culpa com previsão ou consciente. Um empregado de fazenda provoca involuntariamente o incêndio de um celeiro cheio de feno, onde, ao fim do 
dia, tinha ido fumar o seu cachimbo, prevendo, embora, que daí resultasse o fogo. Se ele esperou sinceramente que tal resultado não ocorresse e por isso aventurou-se ao ato imprudente, o seu caso é de culpa com previsão. Se porém, por causa de uma rusga com o patrão, por exemplo, pouco se lhe dava que esse resultado previsto ocorresse ou não, o que se configura é o dolo eventual. (WEZEL, 1971, p. 38).

Ou seja, em ambos os casos, de dolo eventual ou culpa consciente, o agente sabe do resultado, porém, diferentemente do primeiro, a culpa consciente, para que exista, o autor dos fatos se preocupa em não alcançar o resultado. Mesmo que realize a conduta, acredita que não irá produzi-lo, o que no dolo eventual se mostra a indiferença do indivíduo, com relação a alcançar ou não o resultado.

Nas palavras de Luiz Regis Prado:

(...) o critério decisivo se encontra na atitude emocional do agente. Sempre que, ao realizar a ação, conte com a possibilidade concreta de realização do tipo de injusto será dolo eventual. De outra parte, se confia que o tipo não se realize, haverá culpa consciente (...). (PRADO, 2006, p. 367).

Desta forma, se mostra factível que o fator primordial para diferenciar ambos institutos está ligado ao objetivo de alcançar ou não o resultado, por mais que este seja previsto; no caso da culpa consciente, o autor dos fatos não quer que o resultado se concretize, ele não realiza a conduta acreditando que alcançará o resultado, vez que este somente ocorre, por uma negligência, por uma falta de cuidado do agente.

Como já devidamente elucidado, na culpa consciente, o agente sabe que sua conduta poderá gerar um resultado e, de forma implícita, conquanto apenas acredite que o resultado não ocorrerá, opta pela consecução de seus atos. Em outras palavras, extrema sua responsabilidade em uma linha tênue entre o dolo (com maior incidência) e a boa-fé, de modo que, alternativa não haverá quando da ocorrência do resultado, senão a máxima responsabilidade na modalidade culposa seja pela negligência, imprudência ou imperícia durante a execução do ato.

Fernando Capez é claro e objetivo ao dizer que:

A culpa consciente difere do dolo eventual, porque neste o agente prevê o resultado, mas não se importa que ele ocorra ('se eu continuar dirigindo assim, posso vir a matar alguém, mas não importa; se acontecer, tudo bem, eu vou prosseguir'). Na culpa consciente, embora prevendo o que possa vir a acontecer, o agente repudia essa possibilidade ('se eu continuar dirigindo assim, posso vir a matar alguém, mas estou certo de que isso, embora possível, não ocorrerá'). O traço distintivo entre ambos, portanto, é que no dolo eventual o agente diz: 'não importa', enquanto na culpa consciente supõe: 'é possível, mas não vai acontecer de forma alguma. (CAPEZ, 2010, p.187).

De acordo com o que preceitua Rogério Grecco, "na culpa consciente, o agente, embora prevendo o resultado, acredita sinceramente na sua não-ocorrência; o 
resultado previsto não é querido ou mesmo assumido pelo agente". (GRECCO, 2006, p. 218).

No caso do dolo eventual, a intenção do agente, conquanto não se correlacione com a vontade de produzir o resultado, é de assumir as consequências de sua produção, afinal, detém capacidade para compreender que a conduta que irá praticar resultará em um evento danoso, o que se torna indiferente, sendo que irá praticar o ato de qualquer forma.

Acerca do assunto, Damásio de Jesus, dispõe sobre o assunto: “quando o sujeito assume o risco de produzir o resultado, i.e., admite e aceita o risco de produzi-lo" (JESUS, 1991, p. 50).

Nas palavras de Edgard Noronha:

No dolo eventual, o sujeito prevê o resultado e, embora não o queira propriamente atingi-lo, pouco se importa com a sua ocorrência ("eu não quero, mas se acontecer, para mim tudo bem, não é por causa deste risco que vou parar de praticar minha conduta - não quero, mas também não me importo com a sua ocorrência"). (NORONHA, 2009, p. 135) (grifos nossos).

Acerca do dolo eventual, especificamente no que diz respeito à temática central da presente pesquisa, evidente que a intenção do autor é consumar o ato, afinal, dele se beneficiará. É, exatamente, se satisfazer na remota possibilidade de condenação que, se existente, será em grau mínimo. Trata-se, de elemento característico da Teoria da Cegueira Deliberada, vez que esta ocorre toda vez que o sujeito sabendo ou devendo saber que a consagração daquele ato, é proveniente de uma conduta penal anterior, não lhe dá a menor importância.

Sobre o tema, exemplifica Renato Brasileiro de Lima, que:

Personifica essa situação, o comerciante de joias que suspeita que alguns de seus clientes possam estar lhe pagando pela compra de joias com dinheiro sujo, com o fito de ocultar a proveniência ilícita dos valores, escolhendo, assim mesmo, criar barreiras para não tomar conhecimento de informações mais precisas de seus clientes. (LIMA, 2016, p.326) (grifos nossos).

Nas palavras de Sérgio Fernando Moro:

A doutrina da cegueira deliberada tem sido admitida pela justiça norte-americana quando presentes dois requisitos, quais sejam, quando há prova de que o agente tinha ciência da alta possibilidade de que os bens, direitos ou valores envolvidos eram oriundos de infração penal, e quando o agente age de maneira indiferente a tal ciência (MORO, 2010). (grifos nossos).

E, pelo entendimento de Eugenio Raúl Zaffaroni e José Henrique Pierangeli: 
(...) culpa consciente, aquela em que o sujeito ativo representou para si a possibilidade da produção do resultado, embora a tenha rejeitado, na crença de que, chegado o momento, poderá evitá-lo ou simplesmente ele não ocorrerá. Este é o limite entre a culpa consciente e o dolo [...]. Aqui há um conhecimento efetivo do perigo que correm os bens jurídicos, que não se deve confundir com a aceitação da possibilidade de produção do resultado, que é uma questão relacionada ao aspecto volitivo e não ao cognoscitivo, e que caracteriza o dolo eventual. Na culpa com representação, a única coisa que se conhece efetivamente é o perigo. (Zaffaroni e Pierangeli, 2011, p. 450).

Daí o porquê, se preenchidos todos os elementos constitutivos da Cegueira Deliberada na conduta praticada pelo agente, quais sejam, a possibilidade de saber que o que lhe está sendo proposto é oriundo de uma infração penal antecedente, e mesmo assim opta por ignorá-la, unicamente para alcance do objetivo, não há ou não deveria haver argumentos plausíveis e suficientes para descaracterizar o dolo eventual, no intuito (subsidiariamente precípuo) de que seja acolhida a culpa consciente, vez que, demonstrado anteriormente, a diferença entre os elementos é tão somente o risco do resultado. Assim, para o autor do fato punitivo, que "fecha seus olhos" para todos os resquícios de uma infração anterior, almejando um desfecho favorável, agindo, aliás, diretamente com dolo, não deverá ou não deveria haver qualquer possibilidade de caracterização da modalidade culposa neste quesito.

\section{LEI DE LAVAGEM DE CAPITAIS}

Em 1998, por meio da Lei de $n^{\circ} 9.613$, foi devidamente tipificado o crime de lavagem de dinheiro, dessa forma, constituído como delito independente, ou seja, está a parte do Código Penal Brasileiro. De forma simples, meio pelo qual, o legislador estabeleceu a responsabilidade daqueles que obtêm valores em geral, de maneira ilícita.

Na publicação da Lei, o artigo $1^{\circ}$, demonstrou de forma clara, que para a caracterização do crime de lavagem de dinheiro, necessário se fazia a ocorrência de crime anterior. Trouxe, inclusive, quais os delitos que poderiam incorrer preteritamente para a prática do crime, conforme texto abaixo:

\footnotetext{
“Art. $1^{\circ}$ Ocultar ou dissimular a natureza, origem, localização, disposição, movimentação ou propriedade de bens, direitos ou valores provenientes, direta ou indiretamente, de crime:

I - de tráfico ilícito de substâncias entorpecentes ou drogas afins;

II - de terrorismo;

III - de contrabando ou tráfico de armas, munições ou material destinado à sua produção;

IV - de extorsão mediante seqüestro;

V - contra a Administração Pública, inclusive a exigência, para si ou para outrem, direta ou indiretamente, de qualquer vantagem, como condição ou preço para a prática ou omissão de atos administrativos;

VI - contra o sistema financeiro nacional;

VII - praticado por organização criminosa.

Pena: reclusão de três a dez anos e multa. (BRASIL, Lei 9.613, 1998 - grifos nossos)".
} 
Em 2002, houve a inclusão do inciso VIII, pela Lei de $\mathrm{n}^{\circ} 10.467$, com a seguinte redação, acrescentando, também, quando: "praticado por particular contra a administração pública estrangeira (arts. 337-B, 337-C e 337-D do Decreto-Lei $\mathbf{n}^{0}$ 2.848, de 7 de dezembro de 1940 - Código Penal)". No ano de 2003, a Lei de $\mathrm{n}^{\circ}$ 10.701 alterou a redação do inciso II, em que passou a constar além do terrorismo, o financiamento deste crime.

Após alguns anos, este artigo sofreu consideráveis modificações pela Lei de $\mathrm{n}^{\circ}$ $12.683 / 12$, em que todos os incisos foram revogados, de modo que incorporados apenas no caput.

\footnotetext{
"Art. 1o Ocultar ou dissimular a natureza, origem, localização, disposição, movimentação ou propriedade de bens, direitos ou valores provenientes, direta ou indiretamente, de infração penal.

Pena: reclusão, de 3 (três) a 10 (dez) anos, e multa. (BRASIL, Lei 12.683, 2012 - grifos nossos)".
}

Por mais que a nova redação tenha reduzido o artigo consideravelmente, de certa forma o tornou mais amplo. A redação original do texto da lei delimitava que a prática de lavagem de dinheiro somente se caracterizaria quando o crime pretérito fosse um daqueles relacionados nos respectivos incisos. Atualmente, a redação da lei abrange diversas possibilidades diferentes de se acarretar a lavagem de capitais. Para tanto, basta que haja infração penal anterior, sublinhe-se, independentemente de sua natureza, desde que tenha o condão de caracterizar a existência de uma possível utilização de sistemas financeiros de forma ilícita.

Vale salientar que a lavagem de capital possui como tipo subjetivo o dolo eventual, acreditando-se que o agente tem plena consciência de que está praticando uma das ações previstas no caput do artigo $1^{\circ}$, da referida Lei, sabendo ou devendo saber que o objeto utilizado é de origem ilícita, assumindo os riscos do que está sendo feito. Neste sentido, não se admite a utilização da culpa, não é possível que o agente alegue imprudência, negligência ou imperícia. Mas ainda, se comprovado o erro de tipo, previsto no artigo 20, do Código Penal, é possível a exclusão do dolo.

Nas palavras de Antônio Sérgio A. de Moraes Pitombo:

Entende-se que o dolo, no delito de lavagem de dinheiro, ostenta-se dolo
direto, não obstante tenha sido retirado do anteprojeto da lei a expres-
são "sabendo serem oriundos", a fim de, pretensamente, abrigar o dolo
eventual. Parte dos autores, ao examinar o art. $1^{\circ}$, caput e $\S 1^{\circ}$, da Lei
9.613/1998, afirma a possibilidade de o agente assumir o risco de pro-
duzir o resultado (art. 18, I, in fine, CP). Entretanto, a intencionalidade
de ocultar ou dissimular não dá abrigo à assunção de risco; ao contrário,
exige ação com conhecimento prévio do crime-base, conduzida a partir
da decisão de alcançar o resultado típico. (PITOMBO, 2003, p. 136-137).

A Lei não somente tem a precaução em localizar e penalizar aqueles que possam ter praticado a chamada "lavagem de capitais", como também prevê formas 
eficazes de monitorar as atividades financeiras que sejam incomuns, sendo possível ainda, evitar a prática de novas circunstâncias. Uma das ferramentas utilizadas é o Conselho de Atividade Financeira (COAF), previsto no Capitulo IX, da Lei 9.613/98. A COAF, trata-se de uma unidade de inteligência, que faz parte da GAFI, e é diretamente ligado à SNJ (Secretaria Nacional de Justiça), do Ministério da Justiça do Brasil, por meio do SISCOAF (Sistema de Controle de Atividade Financeira) e monitora toda e qualquer atividade financeira que seja incompatível com a legislação vigente.

Nos crimes que têm por objeto a "lavagem de dinheiro", o elemento subjetivo se caracteriza pelo dolo eventual, ou seja, pela assunção do resultado, independentemente de querê-lo ou não.

Suplementarmente, um dos fundamentos na aceitação do dolo eventual de cunho lógico é sustentado pela inexistência de elemento indicativo de dolo no caput do artigo $1^{\circ}$ da Lei $n^{\circ}$. 9.613/98 o que, por si só, constituiria o dolo na modalidade direta e eventual. Além do comando teleológico da referida Lei, cujo objeto é o combate à lavagem de capitais, isto é, sujeitos e grupos profissionalizados no delito de lavagem, que dificilmente têm notícia sobre a origem do objeto material ilícito. (PRADO, 2013, p. 284).

Objetivando-se, assim, à escusa de tal acusação, os infratores se utilizam do desconhecimento da origem desses objetos para que possam, de alguma forma, afastar o pleito condenatório. Dessa forma, a Teoria da Cegueira Deliberada vem demonstrando ser uma forte fundamentação para que aquele que alegar o desconhecimento da fonte ilícita, seja condenado pela prática da lavagem de capitais, haja vista que auferiu vantagem, sem que tivesse sido dada a devida importância para todo o início, mais especificadamente, de onde veio o objeto.

\section{CASOS OCORRIDOS NO BRASIL}

De forma breve, serão elucidados os três casos de maior proporção pela mídia, em que a Teoria da Cegueira Deliberada fora utilizada para fundamentar as decisões dos Magistrados, são eles: a Ação 470 (popularmente conhecida como "Mensalão"), Ação Lava Jato e o Assalto ao Banco Central.

$\mathrm{O}$ "Mensalão" trata-se de um esquema de compra de votos, envolvendo a Empresa Brasileira de Correios e Telégrafos (ECT), funcionários, políticos e empresas, que custeavam a compra de votos para a própria vantagem, por meio de contratos altamente lucrativos. Durante as investigações, foram descobertos outros esquemas, que ligavam diretamente os partidos políticos, deixando clara a origem desconhecida dos valores que foram utilizados para amparar os parlamentares, sendo descoberto, posteriormente, que o dinheiro estava sendo desviado das verbas públicas.

Instaurada a CPI dos Correios, mesmo sem provas concretas do crime ocorrido, qual seja, o de corrupção, nenhum dos acusados apresentava defesas que fossem suficientes a ensejar a sua inocência. Grande parte dos investigados se limitou a alegar o desconhecimento da ilicitude da origem do dinheiro, o que levou o Tri- 
bunal a visualizar a possibilidade de que os agentes pudessem ter agido com dolo eventual, além de que, preferiram a ignorância, ao invés de procurar saber sobre a realidade dos fatos, ou seja, a real origem do dinheiro que estavam recebendo.

O desdobramento da Ação 470, que se findou em 2013, localizou um esquema muito maior que a compra de votos, o que levou ao início da Ação Lava Jato. A Teoria da Cegueira Deliberada passou a ser constantemente utilizada, possibilitando a condenação dos parlamentares que se delimitaram a alegar o desconhecimento do desvio de dinheiro dos cofres públicos, sem que realmente se importassem com a origem do que estava custeando, por exemplo, suas campanhas.

De forma resumida, a Ação Lava Jato tem como objeto principal a busca pelos envolvidos em crimes como a lavagem de dinheiro e a corrupção, e decorrentes destes, uma eventual formação de quadrilha. Por falta de fundamento legal para que pudessem justificar os desvios ocorridos, alguns utilizaram o desconhecimento, para que fosse possível finalizar as investigações, sem que houvesse uma condenação justa pelos crimes praticados.

Dentre os condenados da Ação Lava Jato, Adir Assad foi acusado ao ser descoberto que suas empresas foram contratadas para repassar o valor de $\mathrm{R} \$ 18 \mathrm{mi}$ lhões para empregados da Petrobrás. Em defesa, o empresário alegou que não participava do dia a dia da empresa, para que pudesse saber o que estava sendo negociado nos contratos, que continham a corrupção ocorrida dentro da estatal. Em sentença, a alegação de desconhecimento por parte do empresário não foi suficiente para acarretar sua absolvição, haja vista que, mesmo não sabendo do plano de corrupção, Assad recebia os pagamentos e tinha ciência da lavagem de dinheiro. A condenação foi de 8 anos e 4 meses

Outro caso foi o do empresário Delmo Pereira Vieira, que teve sua acusação baseada no desvio de $\mathrm{R} \$ 5,75$ milhões, pela empresa Andrade Gutierrez, ao longo das obras de Angra Três, para pagamento de propina. A defesa foi baseada na confissão, quanto ao pagamento em dinheiro para os funcionários da empreiteira, negando somente o destino dos recursos. Em sentença, o juiz Marcelo Bretas reconheceu a possibilidade de que o réu não teria conhecimento da corrupção, porém, pelo modo que se deu o transporte do dinheiro, deveria ter desconfiado de que estavam sendo cometidos crimes e dos riscos aos quais estava sendo exposto. A condenação foi de 4 anos e 6 meses.

De forma clara e objetiva, restou demonstrada a importância da utilização da teoria norte-americana, para que exista a possibilidade de condenação daqueles que agem sabendo dos riscos, ignorando a fonte do dinheiro recebido, desde que a vantagem seja alcançada, sendo de grande importância, inclusive, para as investigações da Lava Jato, contribuindo para a condenação de alguns casos, como os que foram relatados no presente trabalho.

Quanto ao Assalto ao Banco Central, em Fortaleza/CE, este ocorreu no dia 06 de agosto de 2005. Vale ressaltar que foi em uma noite de sexta para o sábado, sendo descoberto somente na manhã da segunda-feira após o início do expediente bancário. A Teoria da Cegueira Deliberada surge no caso do Assalto ao Banco 
Central quando os responsáveis pelo assalto, na manhã do sábado, após o assalto, se dirigiram até uma concessionária, onde adquiriram o total de 11 veículos, que foram pagos em espécie, mais especificadamente no montante de um milhão de reais, em uma cristalina tentativa de lavagem de dinheiro.

Em $1^{a}$ instância, os proprietários da concessionária de veículos foram declarados culpados por não se aterem ao fato de que os veículos estavam sendo pagos em espécie. $\mathrm{O}$ fundamento da decisão fora delineado pela Teoria do Avestruz, de modo que tamparam os olhos para auferir a vantagem que a venda dos veículos lhes proporcionaria. Em sede recurso, Tribunal Regional Federal da $5^{a}$ Região, reformou a decisão proferida, absolvendo os investigados pelo lapso temporal, vez que, no sábado que ocorreu a compra dos veículos, o crime sequer havia sido descoberto.

Dessa forma, é possível concluir, no que diz respeito à proficuidade da Teoria da Cegueira Deliberada, especificamente no assalto ao Banco Central de Fortaleza, que sua primeira tentativa de aplicação no ordenamento jurídico se demonstrou relativa, pois, para que houvesse a efetiva condenação dos donos da concessionária (em que os veículos foram adquiridos), necessário se fazia a decorrência do requisito principal, qual seja, o de "fechar dos olhos" para auferir vantagem ilícita.

\section{RECUPERAÇÃO DE ATIVOS (POSSIBILIDADE DE RESSARCIMENTO)}

O crime de lavagem de capitais sustenta uma bagagem significativa de organizações criminosas, de modo que somente localizar o chefe da quadrilha não se torna o suficiente, vez que este facilmente pode ser substituído por outro, e assim sucessivamente.

Levando isso em consideração, o Estado necessita de medidas diretas, contundentes e eficazes, para combater as organizações criminosas, que são criadas com o objetivo de desenvolver atividades financeiras de forma ilícita.

Desta forma, a recuperação de ativos de origem ilícita, se tornou uma das principais formas de combater as organizações criminosas. Para isso, criou-se o Departamento de Recuperação de Ativos e Cooperação Jurídica Internacional (DRCI), no âmbito da Secretaria Nacional de Justiça (Senajus) do Ministério da Justiça e Segurança Pública (MJSP), que desempenha papel de grande importância para a eficaz recuperação dos ativos.

De acordo com Justiça e Segurança Pública, as atividades desenvolvidas por esses órgãos são:

a) Articular e colaborar com as polícias, o Ministério Público, o Judiciário e os órgãos competentes para recuperar, no Brasil e no exterior, ativos derivados de atividades ilícitas.

b) Implementar, na qualidade de autoridade central no âmbito da cooperação jurídica internacional, ações referentes à recuperação de ativos. c) Elaborar estudos para o aperfeiçoamento e a implementação de mecanismos destinados à recuperação dos instrumentos e dos produtos de crimes, objeto da lavagem de dinheiro.

d) Disponibilizar informações e conhecimentos relacionados ao combate à lavagem de dinheiro, à identificação de crimes antecedentes e à recuperação de ativos no Brasil e no exterior. 
e) Subsidiar e fornecer elementos para auxiliar a instrução de processos que visam à recuperação de ativos.

f) Fornecer subsídios, onde possível, para a gestão e alienação antecipada de ativos.

Fonte: Ministério da Justiça e Segurança Pública (disponível em: https:// www.justica.gov.br/sua-protecao/lavagem-de-dinheiro/recuperacao-de-ativos-1

De acordo com Antônio Carlos Valadares,

A melhor forma de combater o crime organizado é por meio do estrangulamento financeiro. Não basta - embora seja indispensável - efetuar a prisão dos agentes, pois esses são substituídos rapidamente as organizações criminosas continuam agindo. Contudo, suprimindo os meios pelos quais a criminalidade atua, atinge-se o "coração" da organização. A inteligência, aqui, é mais eficaz que a pólvora. (VALADARES, 2012, p. 26 - 27).

Para que a recuperação de ativos seja eficaz, é necessário que se localize o autor do crime, bem como, qual produto utilizado, iniciando a busca pelos rastros que foram deixados pelos agentes durante o percurso da ação delituosa. Finalizada essa fase, poderão ser iniciadas as buscas pelos ativos, no Brasil, por meio do sistema BACENJUD.

Caso os valores tenham sido enviados a outros países, neste caso é necessário que o magistrado competente e/ou o Ministério Público, solicite ao DRCI que este remeta o pedido ao local em que se encontram os valores. Assim, a Justiça do País em questão se encarregará do respectivo bloqueio. Caso não exista o acordo de cooperação entre o Brasil e o País a que se irá destinar o pedido, deverá ser utilizado o princípio da reciprocidade, que embasa as relações em âmbito internacional.

Mesmo com toda essa estrutura, esse sistema para recuperação de ativos contém falhas, nas palavras de Marco Antônio de Barros e Christiany Pegorari Conte:

Empecilhos de toda ordem prejudicam a obtenção de maior produtividade. A começar pela escassez de recursos humanos, especializados ou não, verificada em alguns órgãos, aliada a uma burocratização interna, e ainda mais prejudicada pela falta de recursos financeiros, além da dificuldade na obtenção de provas lícitas que sirvam às investigações. (BARROS, 2006, p.391 - 404).

A alteração realizada na lei de "lavagem de capitais", no ano de 2012, facilitou a prática de tentativa de recuperação de ativos, vez que revogou o antigo rol taxativo da legislação, ampliando as possibilidades de buscas para um possível ressarcimento, por meio dos sistemas de recuperação de ativos, incluindo a ampliação da lista de atividades que poderão ser supervisionadas e investigadas pela COAF, o que permitiu ainda a possibilidade de bloqueio de ativos e alienação antecipada dos bens, que impede o desfazimento destes, durante o trâmite da ação. Outra ma- 
neira de alcançar a recuperação dos ativos são as ações de ressarcimento de danos e responsabilização por atos de improbidade administrativa, na esfera cível.

Desta maneira, é possível verificar que a legislação vigente, de alguma forma, tentou limitar o poder aquisitivo das organizações criminosas, no claro intuito de tirar-lhes as forças, e poder finalizar essa prática delituosa. A recuperação de ativos, até o momento, é o modo mais qualificado de poder ressarcir os valores que foram retirados de forma ilícita, mesmo que ainda não seja possível o ressarcimento total o trabalho que vem sendo realizado se mostra apto a enriquecer o sistema para favorecer os prejudicados e delimitar os atos realizados pelas organizações criminosas.

\section{CONSIDERAÇÕES FINAIS}

De primeiro momento foi devidamente especificada a origem da Teoria da Cegueira Deliberada e sua aplicabilidade em alguns países. O fato de a teoria norte-americana possibilitar embasamento técnico-jurídico para condenação de casos em que o acusado declara de forma expressa o desconhecimento da origem do objeto, tende a trazer confiança na hora do Estado julgar o processo, de modo a não secundar o enriquecimento ilícito, com amparo máxime na culpa consciente.

Ou seja, é possível se identificar ao longo do processo fatos e provas, que se demonstram suficientes para substancializar a potencial consciência (do agente) de que o objeto da relação é de origem ilícita; leia-se, possivelmente de um crime anterior.

No crime de receptação, por exemplo, ainda que todos os indícios sejam suficientes para caracterização da origem ilícita do produto, quando comprovada a boa-fé do agente - circunstância que mascara o dolo - este é absolvido, ao passo que o desconhecimento da fonte oriunda do objeto é argumento suficiente a ensejar a absolvição. Ainda que a receptação disposta nos artigos 180 e 180-A, do Código Penal, traga diversas modalidades, com cominações de penas diferentes, demonstra-se inseguro seu caráter sancionatório ao depender da caracterização da má-fé daquele que adquiriu o produto de forma ilícita.

Neste sentido, é possível verificar a importância da Cegueira Deliberada no desdobramento do crime de receptação corrido no Brasil, vez que, verificados todos os indícios aparentes de que o agente sabia ou deveria saber que o produto é oriundo de crime anterior, necessário se faz o afastamento de qualquer hipótese de substancialização da boa-fé na afirmação do desconhecimento da origem.

No que diz respeito ao dolo eventual ou minimamente a culpa consciente, estes são de devera importância ao instituto da teoria. Na verdade, a diferenciação de cada tipo subjetivo é requisito necessário para a devida caracterização de que o agente - sabendo da fonte originária do produto ou valor adquirido assume o risco ao adquiri-lo, que é o caso do dolo eventual - quer o resultado, assumindo os riscos de fazê-lo. Diferentemente, na culpa consciente, conquanto o agente preveja o resultado, não acredita na sua ocorrência, mais do que isso, relacionando-se com a sua capacidade, se importa e cuida para que este não ocorra; contudo, contrariamente, por negligência, imprudência ou imperícia, este se materializa. 
Por essa razão, defende-se o reconhecimento do dolo eventual em detrimento da modalidade culposa no crime de receptação, permitindo-se, consequentemente, a aplicabilidade da Teoria da Cegueira Deliberada, cujo precedente em território nacional se deu em três grandes eventos/processos de lavagem de dinheiro, quais sejam: o Assalto ao Banco Central, a Ação Lava Jato e a Ação 470.

Nas ações Lava Jato e Mensalão, a teoria foi devidamente utilizada, quando de forma desesperada os réus se utilizaram do desconhecimento da origem ilícita dos valores no intuito de auferir possível absolvição contrária aos elementos que norteavam os atos realizados para a concretização do crime, que naturalmente permitiam aos agentes compreender que os objetos eram originários de desvios ilícitos.

No caso do Assalto ao Banco Central, a teoria foi utilizada em sentença condenatória proferida pelo juízo de primeira instância, cuja fundamentação expressou que os réus poderiam ou deveriam ter vinculado o dinheiro oferecido com o assalto ocorrido. Em contrapartida, a condenação foi afastada em segunda instância, tendo em vista que a notícia do furto só chegou aos noticiários na segunda-feira, após o início do expediente bancário, na medida em que o crime ocorreu no sábado, não havendo motivos plausíveis para que os réus pudessem vincular o objeto ao assalto ocorrido.

A Lei de "Lavagem de Capitais" surge com a possibilidade de combater as organizações criminosas, formadas para literalmente "lavar" o dinheiro (sujo) - dando-lhe origem lícita para a livre circulação, e ainda, criaram mecanismos de proteção às atividades financeiras, para que fossem localizadas as transações duvidosas e as autoridades competentes, comunicadas a tempo de barrar o andamento do crime.

A recuperação de ativos - possibilidade de ressarcir o dano sofrido pelas vítimas dos crimes pretéritos -, ainda possui falhas, vez que depende de provas concretas acerca do destino dos objetos que, nem sempre são devolvidos em virtude da difícil localização desses ativos.

Dessa forma, conclusivamente, a Teoria da Cegueira Deliberada vem ganhando espaço no âmbito penal, por trazer a possibilidade de condenação daqueles que tentam se esconder por detrás da "boa-fé", decorrente da alegação de desconhecimento da origem ilícita do objeto, para se sobreporem à responsabilização jurisdicional pelos crimes praticados.

Portanto, ainda que a Teoria da Cegueira não tenha sido totalmente inserida no Direito Brasileiro, os julgados existentes na qualidade de precedentes demonstram sua efetividade, pois, ricos em fundamentação. Subsuma-se, outrossim, que sua aplicabilidade tem o condão de se sobrepor às estratégias fundadas nas lacunas normativas.

\section{REFERENCIAS}

AQUINO, Amanda Carvalho de. O controle à prática da lavagem de dinheiro no Brasil: alguns mecanismos de prevenção e repressão. Disponível em: <https://ambitojuridico. com.br/cadernos/direito-penal/o-controle-a-pratica-da-lavagem-de-dinheiro-no-brasil-alguns-mecanismos-de-prevencao-e-repressao/> Acesso em 15 mai 2020. 
AROUCK, Vinicius. A Teoria da Cegueira Deliberada e Sua Aplicabilidade no Ordenamento Jurídico Pátrio. Disponível em: <https:/ / emporiododireito.com.br/leitura/a-teoria-da-cegueira-deliberada-e-sua-aplicabilidade-no-ordenamento-juridico-patrio> Acesso em 12 abr 2020.

Artigo 180 - Código Penal Comentado - Crime de Receptação. Disponível em: <https:/ / www.gabarite.com.br/dica-concurso/277-artigo-180-codigo-penal-comentado-crime-de-receptacao> Acesso em 06 mar 2020.

BALTHAZAR, Ricardo. Folha de São Paulo, 28 de dezembro de 2017. Teoria da 'cegueira deliberada' ampara condenações na Lava Jato. Disponível em: <https:/ / www1.folha.uol. com.br/poder/2017/12/1946478-teoria-da-cegueira-deliberada-ampara-condenacoes-na-lava-jato.shtml> Acesso em 20 abr 2020.

BARROS, Marco Antonio de; CONTE, Christiany Pegorari. Antilavagem de dinheiro: ensaio sobre uma cultura em formação. São Paulo: Revista dos Tribunais, v. 854, n. 95, p.391404, dez. 2006.

BARROS, Marco Antônio de; SILVA, Thiago Minetti Apostólico. Lavagem de ativos: dolo direto e a inaplicabilidade da teoria da cegueira deliberada. Revista dos Tribunais. vol. 957. São Paulo: Ed. RT, jul. 2015.

BELARMINO, Montalban. A teoria da cegueira deliberada e sua aplicação nos crimes de lavagem de dinheiro no Brasil. Disponível em: <https://jus.com.br/artigos/70775/a-teoria-da-cegueira-deliberada-e-sua-aplicacao-nos-crimes-de-lavagem-de-dinheiro-no-brasil/1> Acesso em 12 abr 2020.

BRAGA, Lauriberto. 13 Anos Depois Um dos Líderes do Assalto ao Banco Central é Preso. Estadão, São Paulo, 18 de setembro de 2018. Disponível em: <https:// brasil.estadao. com.br/noticias/geral,13-anos-depois-um-dos-lideres-do-assalto-ao-banco-central-e-preso,70002508100> Acesso em 14 de mai. 2020.

BITENCOURT, Cezar Roberto, Tratado de direito penal parte geral 1. São Paulo: Editora Saraiva, 2012.

BRASIL, Lei no 9.613, de 03 de março de 1998, Lei de Lavagem de Capitais, Brasília - DF, março de 1998. Disponível em: <http:/ / www.planalto.gov.br/ccivil_03/leis/19613.htm> Acesso em 14 mai 2020.

BRASIL. Tribunal Regional Federal $5^{\mathrm{a}}$ Região, 2a Turma. ACR 5520/CE. Relator: Rogério Fialho Moreira. Recife, 9 set. 2008. Disponível em: <https://trf-5.jusbrasil.com.br/jurisprudencia/8249976/apelacao-criminal-acr-5520-ce-0014586-4020054058100/inteiro-teor-15197855>

BUENO, Nicolle Duek Silveira. O Crime de Lavagem de Dinheiro. Disponível: <https:/ / jus.com.br/artigos/39171/o-crime-de-lavagem-de-dinheiro> Acesso em 14 mai 2020.

CABRAL, Bruno Fontenele. Breves comentários sobre a teoria da cegueira deliberada (willful blindness doctrine). Disponível em: <https://jus.com.br/artigos/21395/breves-comentarios-sobre-a-teoria-da-cegueira-deliberada-willful-blindness-doctrine> Acesso em 13 mai 2020. 
CAPEZ, Fernando. Curso de Direito Penal: parte geral. V.1. São Paulo: Saraiva, 2001.

CAPEZ, Fernando. Curso de Direito Penal: Parte Especial. São Paulo, ed. Saraiva, 2004, $4^{\mathrm{a}} \mathrm{ed}$.

CAPEZ, Fernando. Curso de Direito Penal: Parte Geral. São Paulo: Saraiva, 2010.

CAPEZ, Fernando. Curso de Direito Penal - Parte Geral. São Paulo: Editora Saraiva, 2016.

CARVALHO, Rodrigo Pereira. Assalto ao Banco Central de Fortaleza completa 11 anos. Disponível em: < https://www.camara.leg.br/radio/programas/466207-assalto-ao-banco-central-de-fortaleza-completa-11-anos/> Acesso em 06 mai 2020.

CONCEIÇÃO, Arnaldo Alves da. Distinção de dolo eventual e culpa consciente. Disponível em: <https:/ / ambitojuridico.com.br/cadernos/direito-penal/distincao-de-dolo-eventual-e-culpa-consciente/> Acesso em 05 abr 2020.

DUARTE, Lidiane. Mensalão. Disponível em: < https://www.infoescola.com/politica/ mensalao/>, acesso em 13 mai 2020.

FERRAZ, Sérgio Valladão. O valor da Cegueira Deliberada no Sistema de Imputação Brasileiro, a Cegueira Deliberada como indicador qualificado do significado dolo. Curitiba. Ano 2018. Disponível em: <https://acervodigital.ufpr.br/bitstream/handle/1884/57134/R\%20-\%20T\%20-\%20SERGIO\%20VALLADAO\%20FERRAZ.pdf?sequence $=1 \&$ isAllowed $=\mathrm{y}>$ Acesso em 06 mar 2020 .

GRECO, Rogério. Curso de Direito Penal: Parte Geral. v. I. 6. ed. Niterói: Impetus, 2006.

HUNGRIA, Nélson. Comentários ao código penal. v. VII (arts. 155 a 196). $2^{\mathrm{a}}$ ed. Rio de Janeiro: Forense, 1958.

IBIPIANO, Ana Sabrina Fontes. A Lavagem de Capitais e a Teoria da Cegueira Deliberada no Brasil. Ambito Juridico. Disponível em: <https://ambitojuridico.com.br/cadernos/direito-penal/a-lavagem-de-capitais-e-a-teoria-da-cegueira-deliberada-no-brasil/> Acesso em 13 mai. 2020

IRA P. ROBBINS. The Ostrich Instruction: deliberate ignorance as a criminal mens rea, 81 J. CRIM. L. \& Criminology, Chicago, Estados Unidos, ano 1990.

JESUS, Damásio de. Código Penal Comentado. 2. ed. São Paulo: Saraiva, 1991

LEAL, Rodrigo José. Análise crítica do crime de receptação qualificada. Disponível em: <https:/ /jus.com.br/artigos/46185/analise-critica-do-crime-de-receptacao-qualificada> Acesso em 06 mar 2020.

LIMA, Renato Brasileiro de. Legislação criminal especial comentada: volume único. 4. Ed. Ver., atual. e ampl. Salvador: Juspodivm, 2016.

LOUREIRO, Antônio José Cacheado. Operação Lava Jato sob a visão da ética aristotélica. Disponível em: < https:/ / ambitojuridico.com.br/edicoes/revista-170/operacao-lava-jato-sob-a-visao-da-etica-aristotelica/> Acesso em 20 abri 2020. 
MORAES, Guilherme Lozano de. A Teoria da Cegueira Deliberada e o Crime de Violação de Direito Autoral. Disponível em: <https:/ / ambitojuridico.com.br/cadernos/direito-penal/a-teoria-da-cegueira-deliberada-e-o-crime-de-violacao-de-direito-autoral/> Acesso em 06 mar. 2020.

MORO, Sérgio Fernando. Crime de lavagem de dinheiro. ver. digital. São Paulo: Saraiva, 2010 .

NETO, F. SANNINI. Teoria da Cegueira Deliberada e o Crime de Receptação. Jusbrasil, Ano 2013. Disponível em: https://franciscosannini.jusbrasil.com.br/artigos/121943696/ teoria-da-cegueira-deliberada-e-o-crime-de-receptacao, acesso em 10 abr 2020.

NORONHA, E. Magalhães. Direito Penal, , volume II, $13^{a}$ edição. Citar cidade da editora: Saraiva, 2003.

NORONHA, Edgard. Direito Penal: parte geral. 30.ed. São Paulo: Saraiva, 2000. p.129 139. v.1.

NUCCI, Guilherme de Souza. Código Penal Comentado. Rio de Janeiro: Editora Forense. 2017.

Operação Lava Jato. Disponível em: <http:/ /www.pf.gov.br/imprensa/lava-jato> Acesso em 20 abri 2020.

PITOMBO, Antônio Sérgio A. de Moraes. Lavagem de dinheiro: a tipicidade do crime antecedente. São Paulo: Revista dos Tribunais, 2003.

PRADO, Luiz Regis. Curso de direito penal brasileiro. 6.ed. São Paulo: Revista dos Tribunais, 2006.

PRADO, Luiz Regis. Curso de direito penal brasileiro. 12.ed. São Paulo: Revista dos Tribunais, 2013.

RAGUĖS I VALLÈS, Mejor no saber, sobre la doctrina de la ignorancia deliberada en Derecho penal. Barcelona (ES). 2013.

Recuperação de ativos. Disponível em: <https://www.justica.gov.br/sua-protecao/lavagem-de-dinheiro/recuperacao-de-ativos-1> Acesso em 15 mai 2020.

ROMANO, Rogério Tadeu. Receptação: análise doutrinária e jurisprudencial. Disponível em: <https://jus.com.br/artigos/39289/receptacao-analise-doutrinaria-e-jurisprudencial> Acesso em 06 mar 2020.

SILVA, Pedro Hnerique Viana da. Dolo eventual e culpa consciente: conceitos e distinções. Disponível em: < https://ambitojuridico.com.br/cadernos/direito-penal/dolo-eventual-e-culpa-consciente-conceitos-e-distincoes/> Acesso em 11 abr 2020.

Supremo Tribunal Federal. Ação Penal 470. Desmembramento do Processo. 2012. Disponível em: < https:/ / www.conjur.com.br/dl/ap-470-marco-aurelio.pdf> Acesso em 13 mai 2020. 
Supremo Tribunal Federal. Informativo no ${ }^{0}$ 684. Disponível em: < http:/ / www.stf.jus.br/ arquivo/informativo/documento/informativo684.htm> Acesso em 13 mai 2020.

VALADARES, Antônio Carlos. Por um sistema mais eficiente de combate à lavagem de dinheiro. Revista Jurídica Consulex, ano XVI, nº 361, p. 26-27, fev.. 2012.

VENTURA, Denis Caramigo. A “lavagem de dinheiro" e suas peculiaridades. Disponível em: <https://www.direitonet.com.br/artigos/exibir/9623/A-lavagem-de-dinheiro-e-suas-peculiaridades $>$ Acesso em 14 mai. 2020

WELZEL, Hans. Culpa e delitos de circulação. Revista de Direito Penal, Rio de Janeiro: Borsa, 1971.

ZAFFARONI, Eugenio Raúl; PIERANGELI, José Henrique. Manual de direito penal brasileiro: volume 1: parte geral. 9. ed. rev. e atual. São Paulo: Editora Revista dos Tribunais, 2011. 